\title{
Morbillivirus receptors and tropism: multiple pathways for infection
}

\section{Hiroki Sato, Misako Yoneda, Tomoyuki Honda and Chieko Kai *}

Laboratory Animal Research Center, Institute of Medical Science, The University of Tokyo, Tokyo, Japan

Edited by:

Akio Adachi, The University of

Tokushima Graduate School, Japan

\section{Reviewed by:}

Masato Tsurudome, Mie University Graduate School of Medicine, Japan Kaoru Takeuchi, University of Tsukuba, Japan

\section{*Correspondence:}

Chieko Kai, Laboratory Animal Research Center, Institute of Medical Science, The University of Tokyo, 4-6-1 Shirokanedai, Minato-ku, Tokyo 108-8639, Japan.

e-mail: ckai@ims.u-tokyo.ac.jp
Morbilliviruses, which include measles virus (MeV), canine distemper virus, and rinderpest virus, are among the most important pathogens in their respective hosts and cause severe syndromes. Morbilliviruses are enveloped viruses with two envelope proteins, one of which is hemagglutinin $(H)$ protein, which plays a role in binding to cellular receptors. During morbillivirus infection, the virus initially targets lymphoid cells and replicates efficiently in the lymph nodes. The principal cellular receptor for morbillivirus is signaling lymphocyte activation molecule (SLAM, also called CD150), which is exclusively expressed on immune cells. This feature reflects the strong lymphoid cell tropism and viral spread in the infected body. Morbillivirus infection, however, affects various tissues in the body, including the lung, kidney, gastrointestinal tract, vascular endothelium, and brain. Thus, other receptors for morbilliviruses in addition to SLAM might exist. Recently, nectin-4 has been identified as a novel epithelial cell receptor for MeV. The expression of nectin-4 is localized to polarized epithelial cells, and this localization supports the notion of cell tropism since MeV also grows well in the epithelial cells of the respiratory tract. Although two major receptors for lymphoid and epithelial cells in natural infection have been identified, morbillivirus can still infect many other types of cells with low infectivity, suggesting the existence of inefficient but ubiquitously expressed receptors. We have identified other molecules that are implicated in morbillivirus infection of SLAM-negative cells by alternative mechanisms. These findings indicate that morbillivirus utilizes multiple pathways for establishment of infection. These studies will advance our understanding of morbillivirus tropism and pathogenesis.

Keywords: morbillivirus, measles virus, CD46, SLAM, nectin-4, cell tropism

\section{INTRODUCTION}

Morbilliviruses belong to the order Mononegavirales, family Paramyxoviridae, and include measles virus $(\mathrm{MeV})$, rinderpest virus (RPV), and canine distemper virus (CDV). Morbilliviruses are highly contagious for their respective hosts and mediate similar consequences of pathogenesis, such as fever, cough and coryza, and respiratory and gastrointestinal diseases. In particular, induction of severe transient immunosuppression along with the gain of life-long immunity are the most notable features of morbillivirus infection (Griffin, 2007).

Measles virus is a leading cause of mortality in children worldwide. In particular, strong immunosuppression causes secondary infection and leads to high childhood mortality in the developing world. RPV affects several species of wild and domestic clovenhoofed animals. The mortality rate can reach nearly $100 \%$ in highly susceptible cattle or buffalo herds; in fact, rinderpest had caused significant economic damage since records began. CDV is a cause of fatal disease in many species of carnivores. Recently, fatal CDV infection has been reported in other species such as large felids (Appel et al., 1994), javelinas (Appel et al., 1991), and freshwater and marine seals (Visser et al., 1990).

To limit these severe and fatal diseases of morbilliviruses, appropriate measures have been taken, including live attenuated and effective vaccines, which were developed more than 40 years ago and control the viruses well. In particular, international campaigns have been conducted to eradicate both $\mathrm{MeV}$ and RPV globally. As a result of vaccination efforts and culling of infected animals, eradication of rinderpest in all 198 countries and territories was declared by OIE (2011) and FAO (2011). Rinderpest became the second viral disease, after smallpox, to be eradicated through human efforts. In the case of measles, vaccination has contributed to reducing the mortality rate in infants, and deaths due to measles were reduced by $78 \%$ worldwide between 2000 and 2008 (from 733,000 to 164,000) after a global campaign for vaccination (WHO, 2011).

Morbilliviruses are enveloped virions that contain a nonsegmented, negative-stranded RNA genome that encodes a single envelope-associated matrix protein $(\mathrm{M})$, two glycoproteins (hemagglutinin $\mathrm{H}$ and fusion protein $\mathrm{F}$ ), two RNA-polymeraseassociated proteins (phosphoprotein $\mathrm{P}$ and large protein $\mathrm{L}$ ), and a nucleocapsid protein $(\mathrm{N})$ that encapsulates the viral RNA (Figure 1). The $\mathrm{H}$ gene encodes a key protein for morbillivirus and its animal hosts: the virus uses this protein to attach to cell receptors during the first step of infection (Griffin, 2007).

The search for the receptor for morbillivirus began in vaccine strains of $\mathrm{MeV}$, and subsequently identified receptors for wild-type strains have revealed the closely related receptor usage and unique pathogenicity of the viruses. 


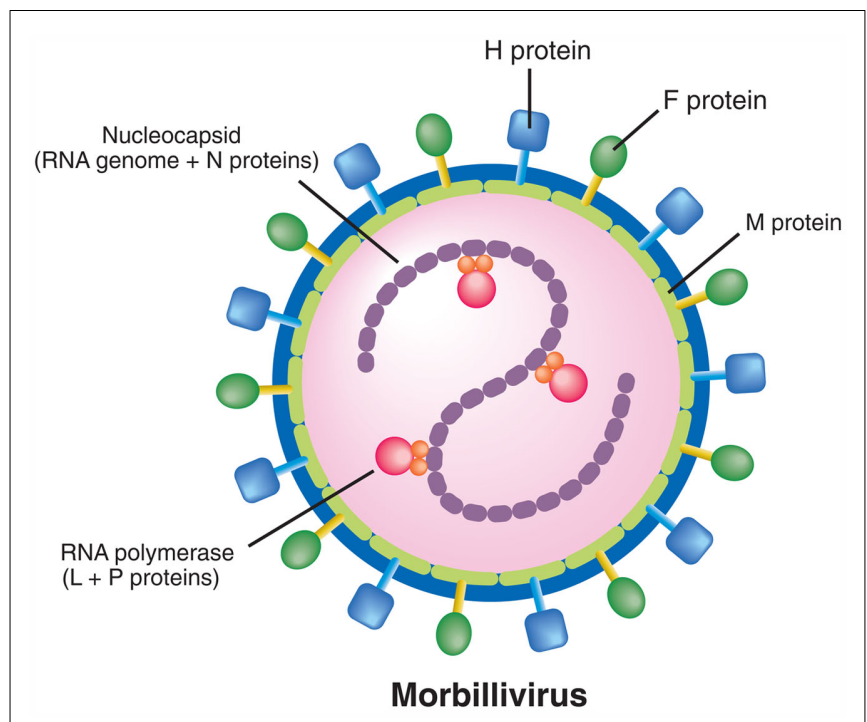

FIGURE 1 | Schematic diagram of the components of the morbillivirus. The viral particle contains the ribonucleoprotein complex consisting of the nucleocapsid (genomic RNA and N proteins) and viral RNA polymerase ( $P$ and $L$ proteins), and the envelope consisting of the $\mathrm{M}, \mathrm{F}, \mathrm{H}$ proteins, and host cell-derived membrane.

In this review, we introduce the identified receptors for morbilliviruses, mainly $\mathrm{MeV}$, and discuss cell tropism and pathogenicity in terms of receptor usage.

\section{CD46}

Measles virus was first isolated by Enders and Peebles (1954) from primary human kidney cells inoculated with the blood and throat washings of a child with measles. The virus strain (Edmonston) was passaged multiple times in primary human kidney and amnion cells and then adapted to eggs and multiply passaged in chick embryo cells to produce the original Edmonston B vaccine, which was licensed in 1963 (Griffin, 2007). Administration of the live attenuated vaccine results in transient immunosuppression, but induces both expression of the neutralizing antibody and cellular immune responses sufficient for protection.

Vero cells derived from the African green monkey kidney had been utilized to isolate $\mathrm{MeV}$ as a standard cell line because it is beneficial and safe. About 40 years after $\mathrm{MeV}$ was isolated, two groups reported in 1993 that CD46 acts as a cellular receptor for laboratory-adapted strains of MeV. Naniche et al. (1992) obtained a monoclonal antibody that inhibited cell fusion induced by recombinant vaccinia virus encoding the $\mathrm{H}$ and $\mathrm{F}$ proteins of the Halle strain of $\mathrm{MeV}$. The antibody precipitated a cell-surface glycoprotein from human and simian cells but not from murine cells. N-terminal amino acid sequencing identified that the glycoprotein was human membrane cofactor protein (CD46), a member of the regulators of the complement activation gene cluster (Naniche et al., 1993). Transfection of non-permissive murine cells with a CD46 expression vector confirmed that the human CD46 molecule serves as a $\mathrm{MeV}$ receptor, allowing virus-cell binding, fusion, and viral replication. Dorig et al. (1993) showed independently that hamster cell lines expressing CD46 produced syncytia and virus proteins after infection with the Edmonston strain of $\mathrm{MeV}$ and that polyclonal antisera against CD46 inhibited virus binding and infection.

CD46 is a cell-surface, type I transmembrane $57-67 \mathrm{kD}$ glycoprotein that belongs to the family of complement activation regulators and is ubiquitously expressed in all nucleated human cells. The most important function of CD46 is as an inhibitor of complement activation. It protects host cells from complement deposition by functioning as a cofactor for the factor-I-mediated proteolytic inactivation of C3b and C4b (Liszewski et al., 1991). In addition, CD46 has been implicated in the modulation of T-cell functions (Marie et al., 2002), generation of regulatory T-cells (Kemper et al., 2003), and control of interferon (IFN) production (Katayama et al., 2000). CD46 is also important during fertilization - it presumably promotes sperm-egg interaction (Riley-Vargas et al., 2004, 2005; Harris et al., 2006).

CD46 exists in multiple isoforms, which are generated by alternative splicing of a single gene. It has four short consensus repeats (SCR 1-4) comprising 60-64 aa each, an alternatively spliced serine/threonine/proline-rich region, a transmembrane region, and an alternatively spliced cytoplasmic tail.

Previous studies have located the $\mathrm{MeV}$ binding site on CD46 to the SCR1 and SCR2 domains of the receptor (Buchholz et al., 1997; Hsu et al., 1997; Casasnovas et al., 1999; Christiansen et al., 2000; Figure 2). Functional studies in vitro have suggested that signaling via $\mathrm{CD} 46$ is an important component of $\mathrm{MeV}$ pathogenesis. For example, the high degree of interaction between $\mathrm{MeV}-\mathrm{H}$ and CD46 results in downregulation of CD46 from the surface of infected cells, rendering them more sensitive to C3b-mediated complement lysis (Schneider-Schaulies et al., 1995a,b; Schnorr et al., 1995). Interestingly, CD46-mediated immunosuppression in $\mathrm{MeV}$ infection has been reported. One mechanism involves inhibiting activation-induced expression of interleukin (IL)-12, which is essential for the generation of successful effector T-cell responses, by cross-linking CD46 on the surface of monocytes by MeV (Karp et al., 1996; Galbraith et al., 1998; Karp, 1999; Kurita-Taniguchi et al., 2000). Interaction of MeV-H and CD46 also induces IL-10, leading to inhibition of the contact hypersensitivity reaction (Marie et al., 2002). In contrast, $\mathrm{MeV}$ binding to CD46 induces IFN production, which further triggers the early antiviral immune response (Manchester et al., 2000; Naniche et al., 2000).

Amino acid residues interacting with CD46 in the $\mathrm{H}$ protein have been identified (F431, V451, Y481, P486, and I487; Masse et al., 2002; Santiago et al., 2002; Vongpunsawad et al., 2004). Among them, two amino acid residues (V451 and Y481) are crucial for determining the ability of $\mathrm{MeV}$ strains to cause hemadsorption, cell fusion, and CD46 downregulation.

\section{ATTENUATION OF MeV PATHOGENICITY BY PASSAGE WITH VERO CELLS}

Although many studies clarified the interaction between $\mathrm{MeV}$ $\mathrm{H}$ and CD46 and the resultant cellular signaling events in vitro, it had also been revealed that these laboratory strains of $\mathrm{MeV}$ do not induce any typical symptoms in non-human primate species, which are susceptible to wild-type $\mathrm{MeV}$. For example, rhesus and cynomolgus macaques have been described to cause 


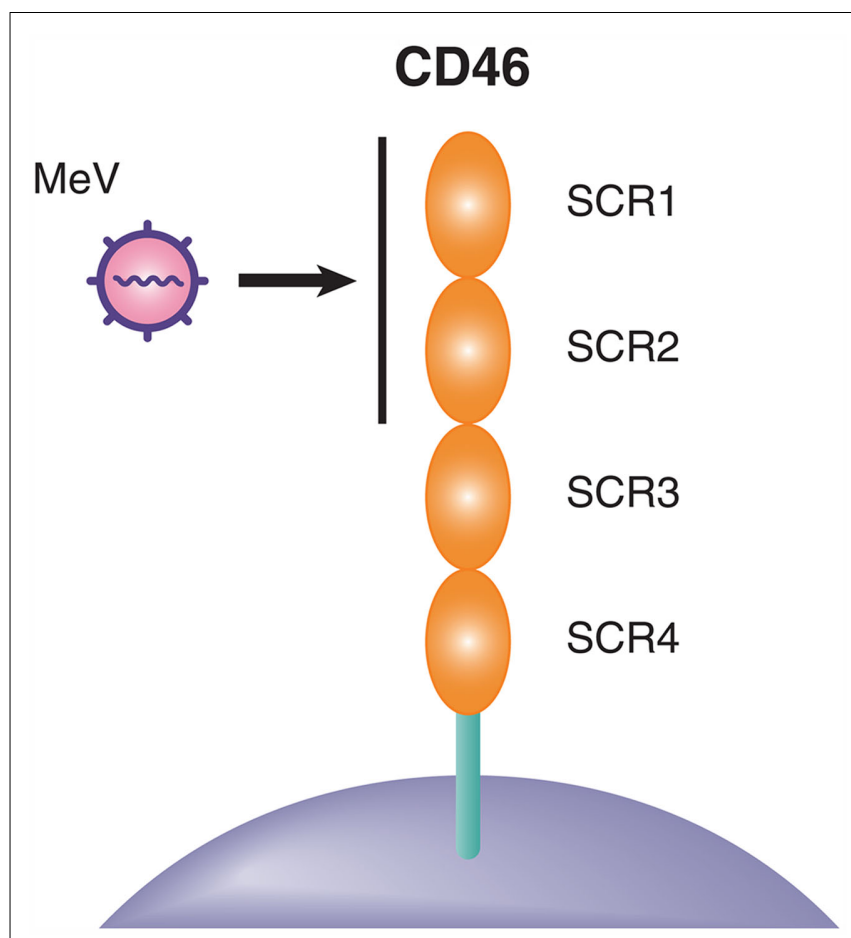

FIGURE 2 | Structure of CD46. CD46 has four SCRs at the amino terminus of its ectodomain. SCR1 and SCR2 interact with the laboratory strains of $\mathrm{MeV}$, whereas SCR3 and SCR4 interact with complement proteins C3b and C4b.

outbreaks of measles in colonies; however laboratory strains of $\mathrm{MeV}$ do not induce disease in these animals (Kobune et al., 1990; van Binnendijk et al., 1994, 1995; McChesney et al., 1997). Furthermore, previous reports indicated that five strains of $\mathrm{MeV}$ that were adapted for growth in Vero cells showed little pathogenicity against experimentally infected macaques, whereas the Bilthoven strain of $\mathrm{MeV}$, which grew in human cord blood cells, induced clinical symptoms of measles (Auwaerter et al., 1999).

Although Vero cells had been used for $\mathrm{MeV}$ isolation for a long time, the isolation was not highly efficient and usually required several blind passages. In contrast, Kobune et al. found that an Epstein-Barr-virus-transformed marmoset B-cell line, B95a, is 10,000 -fold more sensitive to the $\mathrm{MeV}$ present in clinical specimens than Vero cells. Furthermore, MeVs isolated and propagated in B95a cells cause clinical signs in experimentally infected monkeys, which resemble those of human measles such as rashes and Koplik's spots, leukopenia, and marked histological lesions in the lymphoid tissues (Kobune et al., 1990). Subsequently, Kobune et al. $(1990,1996)$ reported that two strains of wild MeV from the same patient, one isolated in B95a cells and the other in Vero cells, had different virulence in monkeys. The former induced acute signs of $\mathrm{MeV}$ infection, whereas the latter did not induce any clinical signs of disease and caused milder histological lesions. These findings strongly indicated that $\mathrm{MeV}$ isolated in B95a cells maintains virulence similar to that in humans and that isolation in Vero cells leads to loss of virulence.
However, strains isolated in B95a cells or human B-cell lines were shown to grow only in a limited number of lymphoid cell lines (Kobune et al., 1990; Schneider-Schaulies et al., 1995b; Tatsuo et al., 2000a). Furthermore, the $\mathrm{H}$ protein of $\mathrm{MeV}$ isolated from B-cell lines neither induced downregulation of CD46 nor caused cell-cell fusion (upon coexpression of the F protein) in CD46-positive cell lines (Lecouturier et al., 1996; Bartz et al., 1998; Tanaka et al., 1998).

From these observations, it had been postulated that B-cell line-isolated strains do not use the ubiquitously expressed CD46 but utilize another molecule as a receptor (Lecouturier et al., 1996; Buckland and Wild, 1997; Bartz et al., 1998; Hsu et al., 1998; Tanaka et al., 1998; Tatsuo et al., 2000a).

\section{SIGNALING LYMPHOCYTE ACTIVATION MOLECULE}

Tatsuo et al. (2000b) performed a screening of a cDNA library of B95a cells, in which a non-susceptible human kidney cell line, 293T, was transfected with the cDNA library and then screened with a vesicular stomatitis virus pseudotype bearing the $\mathrm{H}$ protein of $\mathrm{MeV}$ isolated from B-cells and $\mathrm{F}$ protein from the Edmonston strain. As a result, a single cDNA clone capable of making transfected $293 \mathrm{~T}$ cells susceptible to $\mathrm{MeV}-\mathrm{H}$ protein bearing pseudotype was identified. The sequence of the clone was a homolog of signaling lymphocyte activation molecule (SLAM), and consequently, human SLAM was identified as a lymphoid cell receptor for wildtype $\mathrm{MeV}$. Importantly, the Edmonston strain was found to utilize SLAM, in addition to CD46, as a receptor, indicating that SLAM acts as a receptor not only for B-cell line-isolated $\mathrm{MeV}$ strains but also for vaccine and laboratory-adapted strains (Tatsuo et al., 2000b).

Subsequent studies have demonstrated that MeV strains isolated and propagated by SLAM-positive cells show clinical signs of $\mathrm{MeV}$ in infected animals (van Binnendijk et al., 1994; McChesney et al., 1997; Zhu et al., 1997; Auwaerter et al., 1999; El Mubarak et al., 2007; Bankamp et al., 2008). Therefore, it has been verified that SLAM acts as the principal cellular receptor for $\mathrm{MeV}$ in vivo, and that use of CD46 may be the result of $\mathrm{MeV}$ adaptation in vitro. Furthermore, it has been demonstrated that all CDV and RPV strains use dog and cow SLAM as a receptor, respectively, and that SLAM is a common and principal receptor for morbillivirus (Tatsuo et al., 2001).

Signaling lymphocyte activation molecule is also known as CD150 and is expressed on thymocytes, activated lymphocytes, mature dendritic cells, macrophages, and platelets in humans and mice (Sidorenko and Clark, 1993; Cocks et al., 1995; Aversa et al., 1997). In humans, CD14 ${ }^{+}$monocytes in tonsils and spleens express SLAM (Farina et al., 2004). SLAM is implicated in the regulation of $\mathrm{T}$-cell activation by affecting $\mathrm{T}$-cell antigen receptor signaling. In addition, SLAM has the ability to regulate the functions of several other immune cell types, including natural killer and dendritic cells. Hence, SLAM has a broad involvement in the modulation of innate and acquired immune responses (Veillette and Latour, 2003; Veillette et al., 2007; Schwartzberg et al., 2009).

Signaling lymphocyte activation molecule has two extracellular immunoglobulin superfamily domains, $\mathrm{V}$ and $\mathrm{C} 2$, and is associated with the adaptor molecules, SLAM-associated protein (SAP), or EWS/FliI-activated transcript 2 (EAT-2), in its cytoplasmic tail. 
The extracellular domain of SLAM associates with another SLAM molecule present on adjacent cells. In $\mathrm{CD} 4^{+} \mathrm{T}$-cells, ligation of SLAM induces its binding to SAP, and combined with T-cellreceptor (TCR)-mediated signals, triggers downstream signaling for the production of T helper 2 (Th2) cytokines such as IL-4 and IL-13 (Veillette et al., 2007). Furthermore, SLAM controls production of IL-12, tumor necrosis factor $\alpha$, and nitric oxide, presumably via EAT-2, by macrophages (Veillette et al., 2007).

The $\mathrm{V}$ domain of SLAM is necessary and sufficient for $\mathrm{MeV}$ receptor function and three amino acid residues, at positions 60 , 61, and 63 of human SLAM, are crucial for its function (Ohno et al., 2003; Figure 3). Meanwhile, mutagenesis of the $\mathrm{H}$ protein based on its ability to induce SLAM-dependent cell-cell fusion has revealed that residues important for interaction with SLAM are I194, D505, D507, Y529, D530, T531, R533, H536, Y553, and P554 (Masse et al., 2004; Vongpunsawad et al., 2004; Navaratnarajah et al., 2008).

\section{SLAM ACTS AS THE PRINCIPAL RECEPTOR FOR MORBILLIVIRUS IN VIVO}

Signaling lymphocyte activation molecule-isolated strains express typical clinical symptoms in experimental animal models. Thus, the in vivo study of wild-type morbillivirus, in particular $\mathrm{MeV}$ and CDV, has proceeded in conjunction with the establishment of a novel method for generating recombinant virus, known as reverse genetics (Billeter et al., 2009).

To identify the host cells that support infection, a recombinant CDV that expressed green fluorescent protein (GFP) was produced by reverse genetics, based on a wild-type strain that is lethal to ferrets, and inoculated intranasally into animals (von Messling et al., 2004). CDV initially infected lymphocytes and massively

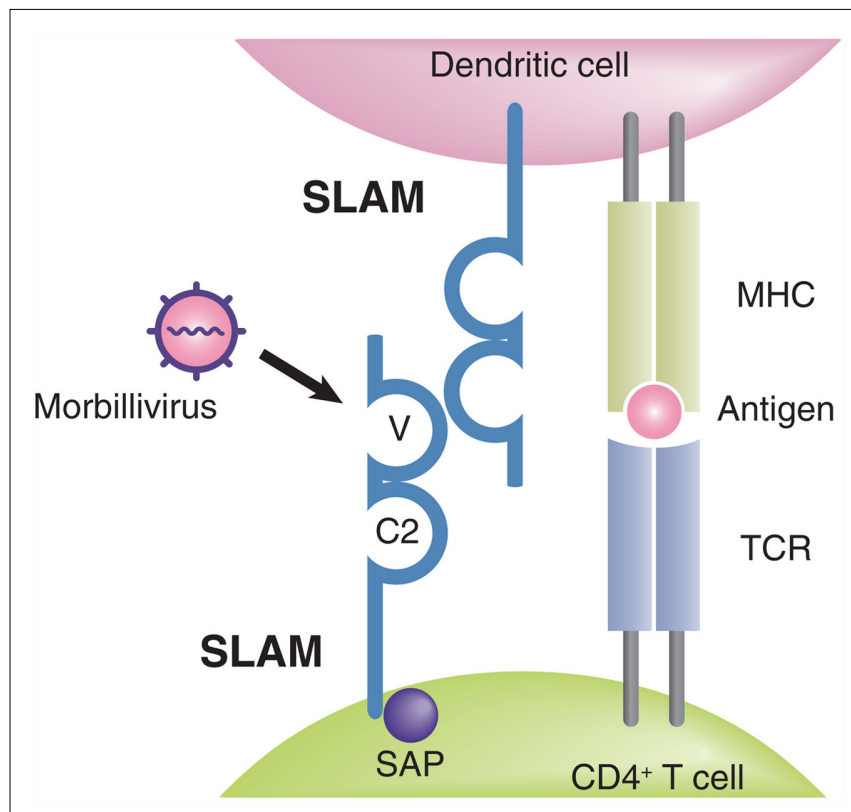

FIGURE 3 | Structure of SLAM. The SLAM extracellular domain is composed of a variable (V) and a constant (C2) Ig-like repeat. SLAM interacts with another SLAM on an adjacent cell. All morbilliviruses bind to the $\mathrm{V}$ domain of SLAM. replicated therein, thereby causing immunosuppression, systemic invasion, and host escape. In contrast, replication in epithelial cells was initially not detectable but substantial before host death.

In a similar manner, GFP-expressing $\mathrm{MeV}$ was also generated and inoculated into macaques via the aerosol route, and the time course of propagation was monitored (de Swart et al., 2007). MeV entered the host at the alveolar level by infecting macrophages or dendritic cells, which carried the virus to bronchus-associated lymphoid tissue, followed by regional dissemination by viremia.

To further clarify the importance of SLAM for morbillivirus pathogenesis, recombinant viruses possessing $H$, which are incapable of recognizing SLAM but can enter epithelial cells (SLAM-blind), have been generated.

Signaling lymphocyte activation molecule-blind CDV infected primary ferret epithelial cells as efficiently as the parental wildtype CDV but was incapable of entering ferret peripheral blood mononuclear cells in vitro. Experimentally infected ferrets indicated that the SLAM-blind virus is completely avirulent in ferrets; infection with this virus caused only a small, short-lived decrease in the blood leukocyte count (von Messling et al., 2006).

Signaling lymphocyte activation molecule-blind $\mathrm{MeV}$ was also generated and inoculated intranasally into rhesus monkeys. As a result, the virus showed attenuated pathogenicity, inefficient infection of lymphocytes, and induced no clinical symptoms in these animals (Leonard et al., 2010).

Recently, our group has generated SLAM-blind RPV using a lapinized strain (RPV-L). RPV-L is highly virulent in rabbits and exhibits similar pathogenicity as virulent RPV in cattle. Thus, RPV-L-infected rabbits should represent a useful model for studying in vivo pathogenicity after RPV infection. SLAM-blind RPV-L induced few clinical signs, which is in agreement with studies with $\mathrm{CDV}$ and $\mathrm{MeV}$, demonstrating that SLAM recognition is necessary for virulence. The virus was not detected in any of the lymphoid tissues, but was detected in lungs, suggesting that the SLAMblind RPV in rabbits could infect epithelial but not lymphoid cells (unpublished data).

These results strongly indicated that SLAM-mediated cell entry is crucial for expression of full pathogenicity of morbillivirus.

\section{A PUTATIVE RECEPTOR ON EPITHELIAL CELLS}

Distribution and functions of SLAM provide a good explanation for the lymphotropism and immunosuppressive nature of morbillivirus. However, morbillivirus, in autopsied patients and some experimentally infected animals, has also been shown to infect the epithelial cells of the trachea, bronchial tubes, lungs, oral cavity, pharynx, esophagus, intestines, liver, and bladder (Griffin, 2007). These epithelial cells do not express SLAM, but the infected cells do shed virus, suggesting that entry into these SLAM-negative cells is mediated by other cellular receptors.

In vitro studies have shown that a number of SLAM-negative cell types of epithelial or neuronal origin result in cytopathic effects and virus release. In particular, several well-differentiated polarized epithelial cell lines showed high susceptibility to wild-type MeV (Takeda et al., 2007; Tahara et al., 2008). Further in vitro studies indicated that wild-type $\mathrm{MeV}$ enters human polarized airway epithelium basolaterally, whereas progeny viral particles are released exclusively from the apical surface of these cells (Tahara 
et al., 2008; Ludlow et al., 2010). Moreover, it was shown that loss of tight junction proteins induced by the transcription repressor SNAIL blocked infection with MeV (Shirogane et al., 2010). These data strongly implied that polarized epithelial cells possess a putative epithelial receptor, EpR, and that the receptor appears to be expressed on the basolateral side of the cells that is associated with tight junctions.

From these studies, before identification of the components of EpR, the region of the $\mathrm{H}$ protein that interacts with the EpR was mapped to the H protein (I456, L464, L482, P497, Y541, and Y543; Leonard et al., 2008; Tahara et al., 2008).

Based on these data, an EpR-blind $\mathrm{MeV}$ maintaining SLAMdependent cell entry was generated and inoculated intranasally into monkeys (Leonard et al., 2008). As a result, EpR-blind MeVinfected macaques developed signs of measles comparable to those of animals infected with wild-type virus, including skin rash and anorexia, indicating that the EpR-blind $\mathrm{MeV}$ remained virulent in the macaques. However, EpR-blind MeV could not be isolated from the tracheal aspirates of all of the monkeys, unlike wild-type $\mathrm{MeV}$. This strongly suggested that $\mathrm{MeV}$ crosses the respiratory epithelium only when it leaves the host and that EpR-blind MeV does not shed in the airways.

\section{NECTIN-4}

In 2011, two independent groups reported identification of the EpR. Both groups utilized microarray data from susceptible versus non-susceptible cell lines and compared the membrane protein gene transcripts.

Noyce et al. (2011) described the susceptibility of many different tumor cell lines to $\mathrm{MeV}$ infection and selected susceptible and non-susceptible cell lines. They filtered the microarray data for membrane protein genes, and produced a short list of 11 candidate receptors. Of these, only human PVRL4 (nectin-4), a tumor cell marker found on breast, lung, and ovarian carcinomas, rendered cells susceptible to $\mathrm{MeV}$ infection. Transient knockdown of nectin4 using siRNA abolished $\mathrm{MeV}$ infection in these cell lines. Furthermore, antibodies specific for human nectin- 4 inhibited $\mathrm{MeV}$ infection. Mühlebach et al. (2011) performed microarray analysis of seven epithelial cell lines from human airways or bladder previously characterized as permissive (three lines) or non-permissive (four lines), and identified that nectin- 4 renders $\mathrm{CHO}$ cells susceptible to $\mathrm{MeV}$. It was demonstrated that the $\mathrm{V}$ domain of nectin-4 binds strongly to MeV-H (Mühlebach et al., 2011; Figure 4).

The nectin family is a cell adhesion molecule family comprising four members (nectin-1-4), and only nectin-4 functions as the EpR (Mühlebach et al., 2011; Noyce et al., 2011). Nectins contain immunoglobulin-like domains, similar to SLAM. The nectin family proteins have recently been shown to be essential contributors to the formation of cell-cell adhesions and are novel regulators of cellular activities, including cell polarization, differentiation, movement, proliferation, and survival (Takai et al., 2008; Ogita et al., 2010). Nectins are also involved in the establishment of apical-basal polarity at cell-cell adhesion sites and the formation of tight junctions in epithelial cells (Takai et al., 2008; Ogita et al., 2010).

To date, details of the interaction mechanism of the newly identified receptor, nectin-4, with $\mathrm{MeV}-\mathrm{H}$ has not been elucidated. In

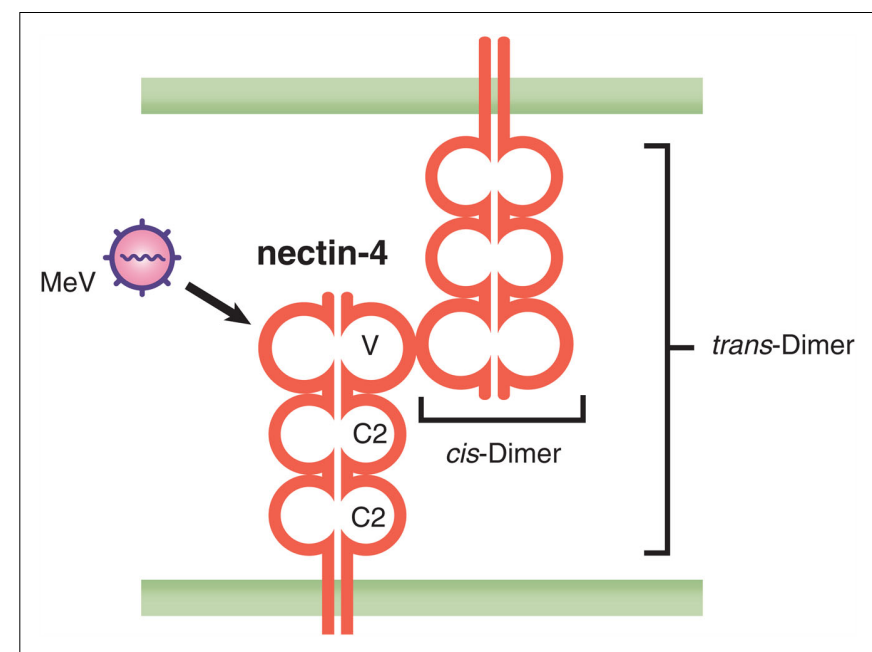

FIGURE 4 | Structure of nectins. The nectin family proteins contain three Ig-like loops ( $\mathrm{V}$ and two C2-type domains) in their extracellular domain. Two nectin and nectin-like molecules of the same plasma membrane first form cis-dimers, and then this is followed by the formation of a trans-interaction between the Ig-like loops of cis-dimers located on opposing cells. MeV binds to the $V$ domain of nectin-4, specifically.

particular, it is unclear whether nectin-4 produces intracellular signals upon engagement with $\mathrm{MeV}-\mathrm{H}$. Further studies are necessary to clarify the implications of the interaction of $\mathrm{MeV}-\mathrm{H}$ and nectin-4 in $\mathrm{MeV}$ pathogenicity.

\section{OVERVIEW OF MeV PROPAGATION IN THE INFECTED BODY}

It has been postulated that the primary targets of $\mathrm{MeV}$ are SLAMpositive alveolar macrophages, dendritic cells, and lymphocytes of the immune system in the respiratory tract, rather than epithelial cells. This contention is supported by the finding that almost all $\mathrm{CD}_{14}{ }^{+}$monocytes in human tonsils express SLAM. MeV subsequently grows in SLAM-expressing lymphatic cells and spreads to lymph nodes throughout the body. After systemic infection, it is considered that the virus is transmitted from infected lymphocytes and dendritic cells to epithelial cells using nectin- 4 on the basolateral side of epithelial cells, and virus particles are subsequently shed from the apical surface of these cells (Figure 5).

\section{ALTERNATIVE RECEPTORS}

From the above studies, the major transmission mode of morbillivirus, especially $\mathrm{MeV}$, has been drawn. However, many histopathological studies have indicated that morbillivirus is also detected in endothelial and neuronal cells (Griffin, 2007), suggesting the existence of other routes for virus propagation to these cell types. In particular, $\mathrm{MeV}$ and $\mathrm{CDV}$ show strong neuronal tropism, and cause acute and persistent encephalitis (Griffin, 2007), nevertheless neural cells neither express SLAM nor nectin-4. These cells may have their own receptors or be infected by virus via an inefficient receptor.

Previous studies using recombinant morbilliviruses expressing GFP have demonstrated that cell entry independent of SLAM and CD46 (and probably nectin-4) occurs in a variety of cell lines with 


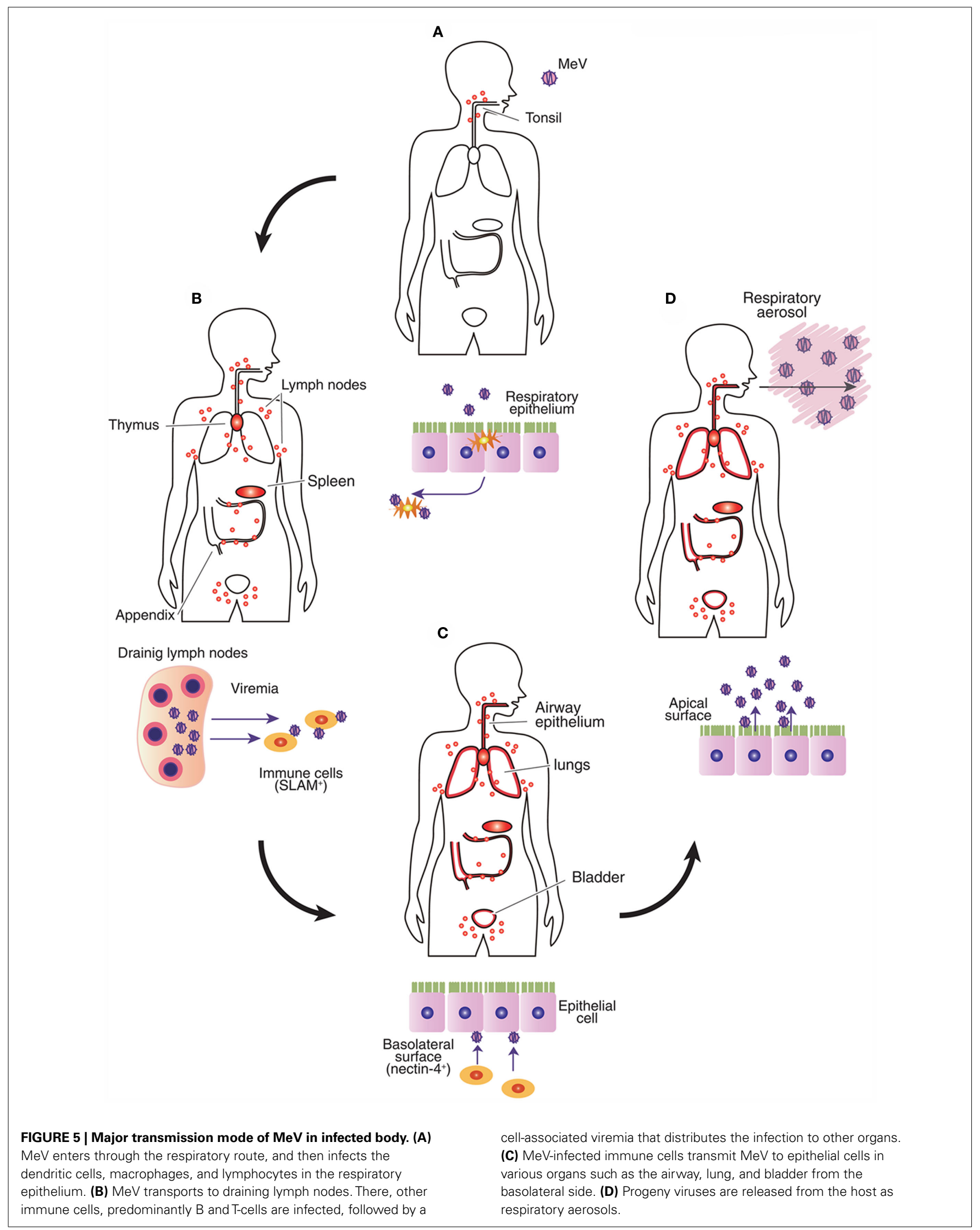


low infectivity (Hashimoto et al., 2002; Fujita et al., 2007; TeraoMuto et al., 2008). This suggests the existence of inefficient but ubiquitously expressed receptors.

Previously, we have found that infection with several SLAM (and presumably nectin-4) negative cell lines with morbillivirus was inhibited by soluble heparin, and that virus bound to immobilized heparin. These results suggest that ubiquitously expressed heparin-like glycosaminoglycans are involved in morbillivirus infection (Fujita et al., 2007; Terao-Muto et al., 2008). More recently, we have also demonstrated a unique infection mechanism of $\mathrm{MeV}$, in which viral particles incorporate cellular cyclophilin (Сyp)B on their surface and bind to cellular CD147, a receptor for CypA and B, independently of MeV-H (Watanabe et al., 2010). It is known that CypA incorporated into HIV-1 particles translocates to the surfaces of virions (Misumi et al., 2002), and that the interaction between CypA and CD147 enables HIV-1 to infect target cells via CD147, independently of the binding of gp120 and CD4 (Pushkarsky et al., 2001). Additionally, severe acute respiratory syndrome coronavirus (SARS-CoV) is proposed to use CD147 as

\section{REFERENCES}

Appel, M. J., Reggiardo, C., Summers, B. A., Pearce-Kelling, S., Mare, C. J., Noon, T. H., Reed, R. E., Shively, J. N., and Orvell, C. (1991). Canine distemper virus infection and encephalitis in javelinas (collared peccaries). Arch. Virol. 119, 147-152.

Appel, M. J., Yates, R. A., Foley, G. L., Bernstein, J. J., Santinelli, S., Spelman, L. H., Miller, L. D., Arp, L. H., Anderson, M., and Barr, M. (1994). Canine distemper epizootic in lions, tigers, and leopards in North America. J. Vet. Diagn. Invest. 6, 277-288.

Auwaerter, P. G., Rota, P. A., Elkins, W. R., Adams, R. J., DeLozier, T., Shi, Y., Bellini, W. J., Murphy, B. R., and Griffin, D. E. (1999). Measles virus infection in rhesus macaques: altered immune responses and comparison of the virulence of six different virus strains. J. Infect. Dis. 180, 950-958.

Aversa, G., Chang, C. C., Carballido, J. M., Cocks, B. G., and de Vries, J. E. (1997). Engagement of the signaling lymphocytic activation molecule (SLAM) on activated T cells results in IL-2-independent, cyclosporin A-sensitive $\mathrm{T}$ cell proliferation and IFN-gamma production. J. Immunol. 158, 4036-4044.

Bankamp, B., Hodge, G., McChesney, M. B., Bellini, W. J., and Rota, P. A. (2008). Genetic changes that affect the virulence of measles virus in a rhesus macaque model. Virology 373, 39-50.

Bartz, R., Firsching, R., Rima, B., ter Meulen, V., and Schneider-Schaulies,
J. (1998). Differential receptor usage by measles virus strains. J. Gen. Virol. 79(Pt 5), 1015-1025.

Billeter, M. A., Naim, H. Y., and Udem, S. A. (2009). Reverse genetics of measles virus and resulting multivalent recombinant vaccines: applications of recombinant measles viruses. Curr. Top. Microbiol. Immunol. 329, 129-162.

Buchholz, C. J., Koller, D., Devaux, Schaulies, J., Braun, W., Gerlier, D., and Cattaneo, R. (1997). Mapping of the primary binding site of measles virus to its receptor CD46. J. Biol. Chem. 272, 22072-22079.

Buckland, R., and Wild, T. F. (1997). Is CD46 the cellular receptor for measles virus? Virus Res. 48, 1-9.

Casasnovas, J. M., Larvie, M., and Stehle, T. (1999). Crystal structure of two CD46 domains reveals an extended measles virusbinding surface. EMBO J. 18, 2911-2922.

Chen, Z., Mi, L., Xu, J., Yu, J., Wang, X., Jiang, J., Xing, J., Shang, P., Qian, A., Li, Y., Shaw, P. X., Wang, J., Duan, S., Ding, J., Fan, C., Zhang, Y., Yang, Y., Yu, X., Feng, Q., Li, B., Yao, X., Zhang, Z., Li, L., Xue, X., and Zhu, P. (2005). Function of HAb18G/CD147 in invasion of host cells by severe acute respiratory syndrome coronavirus. J. Infect. Dis. 191, 755-760.

Christiansen, D., Deleage, G., and Gerlier, D. (2000). Evidence for distinct complement regulatory and measles virus binding sites on CD46 SCR2. Eur. J. Immunol. 30, 3457-3462. P., Mumenthaler, C., Schneider-

a receptor in the same manner as HIV-1 (Chen et al., 2005). Unlike HIV-1 and SARS-CoV, MeV uses CypB instead of CypA for binding to CD147. This finding is the first among viruses belonging to the order Mononegavirales and shows a new infection mode of $\mathrm{MeV}$, which is independent of $\mathrm{H}$ protein.

\section{CONCLUSION}

Investigations aimed at identifying the receptors for morbillivirus started in 1993 with CD46 for vaccine strains of MeV, followed by the lymphoid cell receptor, SLAM, in 2000, and the epithelial cell receptor, nectin-4, in 2011, for wild-type viruses. Along with the receptors, the cell tropism, transmission modes in the body, and unique pathogenicities of morbillivirus are being explained. However, many problems associated with morbillivirus remain to be clarified. In particular, the mechanism by which $\mathrm{MeV}$ spreads in the central nervous system during fatal subacute sclerosing panencephalitis is unknown. Further studies will lead to a better understanding of morbillivirus pathogenesis and to novel strategies for treatment and prevention.

Cocks, B. G., Chang, C. C., Carballido, J. M., Yssel, H., de Vries, J. E., and Aversa, G. (1995). A novel receptor involved in T-cell activation. Nature 376, 260-263.

de Swart, R. L., Ludlow, M., de Witte, L., Yanagi, Y., van Amerongen, G., McQuaid, S., Yuksel, S., Geijtenbeek, T. B. H., Duprex, P., and Osterhaus, A. D. (2007). Predominant infection of CD150+ lymphocytes and dendritic cells during measles virus infection of macaques. PLoS Pathog. 3, e178. doi:10.1371/journal.ppat.0030178

Dorig, R. E., Marcil, A., Chopra, A. and Richardson, C. D. (1993). The human CD46 molecule is a receptor for measles virus (Edmonston strain). Cell 75 295-305.

El Mubarak, H. S., Yuksel, S., van Amerongen, G., Mulder, P. G. Mukhtar, M. M., Osterhaus, A. D., and de Swart, R. L. (2007). Infection of cynomolgus macaques (Macaca fascicularis) and rhesus macaques (Macaca mulatta) with different wild-type measles viruses. J. Gen. Virol. 88(Pt 7), 2028-2034.

Enders, J. F., and Peebles, T. C. (1954). Propagation in tissue cultures of cytopathogenic agents from patients with measles. Proc. Soc. Exp. Biol. Med. 86, 277-286.

FAO. (2011). Global Rinderpest Eradication Programme (GREP). Available at: http://www. fao.org/ag/againfo/programmes/en/ grep/home.html

Farina, C., Theil, D., Semlinger, B., Hohlfeld, R., and Meinl, E. (2004). Distinct responses of monocytes to Toll-like receptor ligands and inflammatory cytokines. Int. Immunol. 16, 799-809.

Fujita, K., Miura, R., Yoneda, M., Shimizu, F., Sato, H., Muto, Y., Endo, Y., Tsukiyama-Kohara, K., and Kai, C. (2007). Host range and receptor utilization of canine distemper virus analyzed by recombinant viruses: Involvement of heparin-like molecule in CDV infection. Virology 359, 324-335.

Galbraith, S. E., Tiwari, A., Baron, M. D. Lund, B. T., Barrett, T., and Cosby, S. L. (1998). Morbillivirus downregulation of CD46. J. Virol. 72, 10292-10297.

Griffin, D. E. (2007). "Measles virus," in Fields Virology, 5th Edn, eds D. M. Knipe, P. M. Howley, D. E. Griffin, R. A. Lamb, M. A. Martin, B. Roizman, and S. E. Straus (Philadelphia, PA: Lippincott Williams \& Wilkins), 1551-1585.

Harris, C. L., Mizuno, M., and Morgan, B. P. (2006). Complement and complement regulators in the male reproductive system. Mol. Immunol. 43, 57-67.

Hashimoto, K., Ono, N., Tatsuo, H., Minagawa, H., Takeda, M., Takeuchi, K., and Yanagi, Y. (2002). SLAM (CD150)-independent measles virus entry as revealed by recombinant virus expressing green fluorescent protein. J. Virol. 76, 6743-6749.

Hsu, E. C., Dorig, R. E., Sarangi, F., Marcil, A., Iorio, C., and Richardson, C. D. (1997). Artificial mutations and natural variations in the CD46 molecules from human and monkey cells define regions important for measles virus binding. J. Virol. 71, 6144-6154. 
Hsu, E. C., Sarangi, F., Iorio, C., Sidhu, M. S., Udem, S. A., Dillehay, D. L., Xu, W., Rota, P. A., Bellini, W. J., and Richardson, C. D. (1998). A single amino acid change in the hemagglutinin protein of measles virus determines its ability to bind CD46 and reveals another receptor on marmoset B cells. J. Virol. 72, 2905-2916.

Karp, C. L. (1999). Measles: immunosuppression, interleukin-12, and complement receptors. Immunol. Rev. 168, 91-101.

Karp, C. L., Wysocka, M., and Wahl, L. M. (1996). Mechanism of suppression of cell-mediated immunity by measles virus. Science 273, 228-231.

Katayama, Y., Hirano, A., and Wong, T. C. (2000). Human receptor for measles virus (CD46) enhances nitric oxide production and restricts virus replication in mouse macrophages by modulating production of alpha/beta interferon. J. Virol. 74, 1252-1257.

Kemper, C., Chan, A. C., Green, J. M., Brett, K. A., Murphy, K. M., and Atkinson, J. P. (2003). Activation of human CD4+ cells with CD3 and CD46 induces a T-regulatory cell 1 phenotype. Nature 421, 388-392.

Kobune, F., Sakata, H., and Sugiura, A. (1990). Marmoset lymphoblastoid cells as a sensitive host for isolation of measles virus. J. Virol. 64, 700-705.

Kobune, F., Takahashi, H., Terao, K., Ohkawa, T., Ami, Y., Suzaki, Y., Nagata, N., Sakata, H., Yamanouchi, K., and Kai, C. (1996). Nonhuman primate models of measles. Lab. Anim. Sci. 46, 315-320.

Kurita-Taniguchi, M., Fukui, A., Hazeki, K., Hirano, A., Tsuji, S., Matsumoto, M., Watanabe, M., Ueda, S., and Seya, T. (2000). Functional modulation of human macrophages through CD46 (measles virus receptor): production of IL-12 p40 and nitric oxide in association with recruitment of protein-tyrosine phosphatase SHP-1 to CD46. J. Immunol. 165, 5143-5152.

Lecouturier, V., Fayolle, J., Caballero, M., Carabana, J., Celma, M. L., Fernandez-Munoz, R., Wild, T. F., and Buckland, R. (1996). Identification of two amino acids in the hemagglutinin glycoprotein of measles virus (MV) that govern hemadsorption, HeLa cell fusion, and CD46 downregulation: phenotypic markers that differentiate vaccine and wild-type MV strains. J. Virol. 70, 4200-4204.

Leonard, V. H., Hodge, G., ReyesDel Valle, J., McChesney, M. B., and Cattaneo, R. (2010). Measles virus selectively blind to signaling lymphocytic activation molecule (SLAM; CD150) is attenuated and induces strong adaptive immune responses in rhesus monkeys. J. Virol. 84, 3413-3420.

Leonard, V. H., Sinn, P. L., Hodge, G., Miest, T., Devaux, P., Oezguen, N., Braun, W., McCray, P. B. Jr., McChesney, M. B., and Cattaneo, R. (2008). Measles virus blind to its epithelial cell receptor remains virulent in rhesus monkeys but cannot cross the airway epithelium and is not shed. J. Clin. Invest. 118, 2448-2458.

Liszewski, M. K., Post, T. W., and Atkinson, J. P. (1991). Membrane cofactor protein (MCP or CD46): newest member of the regulators of complement activation gene cluster. Annu. Rev. Immunol. 9, 431-455.

Ludlow, M., Rennick, L. J., Sarlang, S., Skibinski, G., McQuaid, S., Moore, T., de Swart, R. L., and Duprex, W. P. (2010). Wild-type measles virus infection of primary epithelial cells occurs via the basolateral surface without syncytium formation or release of infectious virus. J. Gen. Virol. 91(Pt 4), 971-979.

Manchester, M., Eto, D. S., Valsamakis, A., Liton, P. B., Fernandez-Munoz, R., Rota, P. A., Bellini, W. J., Forthal, D. N., and Oldstone, M. B. (2000). Clinical isolates of measles virus use CD46 as a cellular receptor. J. Virol. 74, 3967-3974.

Marie, J. C., Astier, A. L., Rivailler, P., Rabourdin-Combe, C., Wild, T. F., and Horvat, B. (2002). Linking innate and acquired immunity: divergent role of CD46 cytoplasmic domains in $\mathrm{T}$ cell induced inflammation. Nat. Immunol. 3, 659-666.

Masse, N., Ainouze, M., Neel, B., Wild, T. F., Buckland, R., and Langedijk, J. P. (2004). Measles virus (MV) hemagglutinin: evidence that attachment sites for MV receptors SLAM and CD46 overlap on the globular head. J. Virol. 78, 9051-9063.

Masse, N., Barrett, T., Muller, C. P., Wild, T. F., and Buckland, R. (2002). Identification of a second major site for CD46 binding in the hemagglutinin protein from a laboratory strain of measles virus (MV): potential consequences for wild-type MV infection. J. Virol. 76, 13034-13038.

McChesney, M. B., Miller, C. J., Rota, P. A., Zhu, Y. D., Antipa, L., Lerche, N. W., Ahmed, R., and Bellini, W. J. (1997). Experimental measles. I. Pathogenesis in the normal and the immunized host. Virology 233, 74-84.
Misumi, S., Fuchigami, T., Takamune, N., Takahashi, I., Takama, M., and Shoji, S. (2002). Three isoforms of cyclophilin A associated with human immunodeficiency virus type 1 were found by proteomics by using two-dimensional gel electrophoresis and matrix-assisted laser desorption ionization-time of flight mass spectrometry. J. Virol. 76, 10000-10008.

Mühlebach, M., Mateo, M., Sinn, P. Prüfer, S., Uhlig, K., Leonard, V., Navaratnarajah, C., Frenzke, M., Wong, X., Sawatsky, B., Ramachandran, S., McCray, P., Cichutek, K., von Messling, V., Lopez, M., and Cattaneo, R. (2011). Adherens junction protein nectin- 4 is the epithelial receptor for measles virus. Nature 480, 530-533.

Naniche, D., Varior-Krishnan, G., Cervoni, F., Wild, T. F., Rossi, B., Rabourdin-Combe, C., and Gerlier, D. (1993). Human membrane cofactor protein (CD46) acts as a cellular receptor for measles virus. J. Virol. 67, 6025-6032.

Naniche, D., Wild, T. F., RabourdinCombe, C., and Gerlier, D. (1992). A monoclonal antibody recognizes a human cell surface glycoprotein involved in measles virus binding. $J$. Gen. Virol. 73(Pt 10), 2617-2624.

Naniche, D., Yeh, A., Eto, D., Manchester, M., Friedman, R. M., and Oldstone, M. B. (2000). Evasion of host defenses by measles virus: wildtype measles virus infection interferes with induction of Alpha/Beta interferon production. J. Virol. 74, 7478-7484.

Navaratnarajah, C. K., Vongpunsawad, S., Oezguen, N., Stehle, T., Braun, W., Hashiguchi, T., Maenaka, K., Yanagi, Y., and Cattaneo, R. (2008). Dynamic interaction of the measles virus hemagglutinin with its receptor signaling lymphocytic activation molecule (SLAM, CD150). J. Biol. Chem. 283, 11763-11771.

Noyce, R., Bondre, D., Ha, M., Lin, L., Sisson, G., Tsao, M., and Richardson, C. (2011). Tumor cell marker PVRL4 (nectin 4) is an epithelial cell receptor for measles virus. PLoS Pathog. 7, e1002240. doi:10.1371/journal.ppat.1002240

Ogita, H., Rikitake, Y., Miyoshi, J., and Takai, Y. (2010). Cell adhesion molecules nectins and associating proteins: implications for physiology and pathology. Proc. Jpn. Acad., Ser. B Phys. Biol. Sci. 86, 621-629.

Ohno, S., Seki, F., Ono, N., and Yanagi, Y. (2003). Histidine at position 61 and its adjacent amino acid residues are critical for the ability of SLAM (CD150) to act as a cellular receptor for measles virus. J. Gen. Virol. 84(Pt 9), 2381-2388.

OIE. (2011). No More Deaths from Rinderpest. Available at: http://www. oie.int/for-the-media/press-releases/ detail/article/no-more-deaths-fromrinderpest/

Pushkarsky, T., Zybarth, G., Dubrovsky, L., Yurchenko, V., Tang, H., Guo, H., Toole, B., Sherry, B., and Bukrinsky, M. (2001). CD147 facilitates HIV-1 infection by interacting with virusassociated cyclophilin A. Proc. Natl. Acad. Sci. U.S.A. 98, 6360-6365.

Riley-Vargas, R. C., Gill, D. B., Kemper, C., Liszewski, M. K., and Atkinson, J. P. (2004). CD46: expanding beyond complement regulation. Trends Immunol. 25, 496-503.

Riley-Vargas, R. C., Lanzendorf, S., and Atkinson, J. P. (2005). Targeted and restricted complement activation on acrosome-reacted spermatozoa. J. Clin. Invest. 115, 1241-1249.

Santiago, C., Bjorling, E., Stehle, T., and Casasnovas, J. M. (2002). Distinct kinetics for binding of the CD46 and SLAM receptors to overlapping sites in the measles virus hemagglutinin protein. J. Biol. Chem. 277, 32294-32301.

Schneider-Schaulies, J., Dunster, L. M., Schwartz-Albiez, R., Krohne, G., and ter Meulen, V. (1995a). Physical association of moesin and CD46 as a receptor complex for measles virus. J. Virol. 69, 2248-2256.

Schneider-Schaulies, J., Schnorr, J. J. Brinckmann, U., Dunster, L. M. Baczko, K., Liebert, U. G., SchneiderSchaulies, S., and ter Meulen, V. (1995b). Receptor usage and differential downregulation of CD46 by measles virus wild-type and vaccine strains. Proc. Natl. Acad. Sci. U.S.A. 92, 3943-3947.

Schnorr, J. J., Dunster, L. M., Nanan, R., Schneider-Schaulies, J., SchneiderSchaulies, S., and ter Meulen, V. (1995). Measles virus-induced down-regulation of CD46 is associated with enhanced sensitivity to complement-mediated lysis of infected cells. Eur. J. Immunol. 25, 976-984.

Schwartzberg, P. L., Mueller, K. L., Qi, H., and Cannons, J. L. (2009). SLAM receptors and SAP influence lymphocyte interactions, development and function. Nat. Rev. Immunol. 9, 39-46.

Shirogane, Y., Takeda, M., Tahara, M., Ikegame, S., Nakamura, T., and Yanagi, Y. (2010). Epithelialmesenchymal transition abolishes the susceptibility of polarized epithelial cell lines to measles virus. J. Biol. Chem. 285, 20882-20890. 
Sidorenko, S. P., and Clark, E. A. (1993). Characterization of a cell surface glycoprotein IPO-3, expressed on activated human $\mathrm{B}$ and $\mathrm{T}$ lymphocytes. J. Immunol. 151, 4614-4624.

Tahara, M., Takeda, M., Shirogane, Y., Hashiguchi, T., Ohno, S., and Yanagi, Y. (2008). Measles virus infects both polarized epithelial and immune cells by using distinctive receptorbinding sites on its hemagglutinin. J. Virol. 82, 4630-4637.

Takai, Y., Miyoshi, J., Ikeda, W., and Ogita, H. (2008). Nectins and nectin-like molecules: roles in contact inhibition of cell movement and proliferation. Nat. Rev. Mol. Cell Biol. 9, 603-615.

Takeda, M., Tahara, M., Hashiguchi, T., Sato, T. A., Jinnouchi, F., Ueki, S., Ohno, S., and Yanagi, Y. (2007). A human lung carcinoma cell line supports efficient measles virus growth and syncytium formation via a SLAM- and CD46independent mechanism. J. Virol.81, 12091-12096.

Tanaka, K., Xie, M., and Yanagi, Y. (1998). The hemagglutinin of recent measles virus isolates induces cell fusion in a marmoset cell line, but not in other CD46-positive human and monkey cell lines, when expressed together with the F protein. Arch. Virol. 143, 213-225.

Tatsuo, H., Okuma, K., Tanaka, K., Ono, N., Minagawa, H., Takade, A., Matsuura, Y., and Yanagi, Y. (2000a). Virus entry is a major determinant of cell tropism of Edmonston and wild-type strains of measles virus as revealed by vesicular stomatitis virus pseudotypes bearing their envelope proteins. J. Virol. 74, 4139-4145.

Tatsuo, H., Ono, N., Tanaka, K., and Yanagi, Y. (2000b). SLAM (CDw150) is a cellular receptor for measles virus. Nature 406, 893-897.

Tatsuo, H., Ono, N., and Yanagi, Y. (2001). Morbilliviruses use signaling lymphocyte activation molecules (CD150) as cellular receptors. J. Virol. 75, 5842-5850.

Terao-Muto, Y., Yoneda, M., Seki, T., Watanabe, A., Tsukiyama-Kohara, K., Fujita, K., and Kai, C. (2008). Heparin-like glycosaminoglycans prevent the infection of measles virus in SLAM-negative cell lines. Antiviral Res. 80, 370-376.

van Binnendijk, R. S., van der Heijden, R. W., and Osterhaus, A. D. (1995). Monkeys in measles research. Curr. Top. Microbiol. Immunol. 191, 135-148.

van Binnendijk, R. S., van der Heijden, R. W., van Amerongen, G., UytdeHaag, F. G., and Osterhaus, A. D. (1994). Viral replication and development of specific immunity in macaques after infection with different measles virus strains. J. Infect. Dis. 170, 443-448.

Veillette, A., Dong, Z., and Latour, S. (2007). Consequence of the SLAMSAP signaling pathway in innatelike and conventional lymphocytes. Immunity 27, 698-710.

Veillette, A., and Latour, S. (2003). The SLAM family of immune-cell receptors. Curr. Opin. Immunol. 15, 277-285.

Visser, I. K., Kumarev, V. P., Orvell, C., de Vries, P., Broeders, H. W., van de Bildt, M. W., Groen, J., Teppema, J. S., Burger, M. C., and UytdeHaag, F. G. (1990). Comparison of two morbilliviruses isolated from seals during outbreaks of distemper in north west Europe and Siberia. Arch. Virol. 111, 149-164.

von Messling, V., Milosevic, D., and Cattaneo, R. (2004). Tropism illuminated: lymphocyte-based pathways blazed by lethal morbillivirus through the host immune system. Proc. Natl. Acad. Sci. U.S.A. 101 14216-14221.

von Messling, V., Svitek, N., and Cattaneo, R. (2006). Receptor (SLAM [CD150]) recognition and the $\mathrm{V}$ protein sustain swift lymphocyte-based invasion of mucosal tissue and lymphatic organs by a morbillivirus. J. Virol. 80 , 6084-6092.

Vongpunsawad, S., Oezgun, N., Braun, W., and Cattaneo, R. (2004). Selectively receptor-blind measles viruses: identification of residues necessary for SLAM- or CD46-induced fusion and their localization on a new hemagglutinin structural model. $J$. Virol. 78, 302-313.

Watanabe, A., Yoneda, M., Ikeda, F. Terao-Muto, Y., Sato, H., and Kai, C. (2010). CD147/EMMPRIN acts as a functional entry receptor for measles virus on epithelial cells. J. Virol. 84 4183-4193.
WHO. (2011). Measles Mortality Reduction: A Successful Initiative. Available at: http://www. who.int/immunization/newsroom/ measles/en/index.html

Zhu, Y. D., Heath, J., Collins, J., Greene, T., Antipa, L., Rota, P., Bellini, W., and McChesney, M. (1997). Experimental measles. II. Infection and immunity in the rhesus macaque. Virology 233, 85-92.

Conflict of Interest Statement: The authors declare that the research was conducted in the absence of any commercial or financial relationships that could be construed as a potential conflict of interest.

Received: 29 December 2011; accepted: 14 February 2012; published online: 01 March 2012.

Citation: Sato H, Yoneda M, Honda T and Kai C (2012) Morbillivirus receptors and tropism: multiple pathways for infection. Front. Microbio. 3:75. doi: 10.3389/fmicb.2012.00075

This article was submitted to Frontiers in Virology, a specialty of Frontiers in Microbiology.

Copyright (c) 2012 Sato, Yoneda, Honda and Kai. This is an open-access article distributed under the terms of the Creative Commons Attribution Non Commercial License, which permits noncommercial use, distribution, and reproduction in other forums, provided the original authors and source are credited. 